\title{
Blockchain and other Distributed Ledger Technologies in Operations*
}

\author{
Volodymyr Babich \\ McDonough School of Business, Georgetown University, Washington, DC 20057 vob2@georgetown.edu
}

Gilles Hilary

McDonough School of Business, Georgetown University, Washington, DC 20057 gilles.hilary@georgetown.edu

\begin{abstract}
Blockchain is a form of distributed ledger technology (DLT) that has grown in prominence, although its full potential and possible downsides are not yet fully understood, especially with respect to Operations Management (OM). This manuscript contributes to filling in this gap. We identify three research themes in applying Blockchain technology to OM, illustrated through several applications to OM problems. Elsewhere, in a companion article, (Babich and Hilary (2018)), we provide a conceptual framework for the role of Blockchain and other DLT in OM, along with specific examples of research questions, and we demonstrate how research in economics can inform research in OM on Blockchain applications. Finally, we discuss possible future uses for the technology.
\end{abstract}

Key words: Visibility, Information aggregation, Validation, Resiliency, Smart contracts, Digital Assets

History: This version: November 14, 2018

\section{Introduction}

Blockchain and other Distributed Ledger Technologies (DLT) are emerging technologies that continue to find more and more applications, yet specific implementations vary widely across platforms and have yet to achieve homogeneity or stability in form. Bitcoin was Blockchain's first notable application; today there are literally thousands of others but the association of Blockchain with cryptocurrencies, often evokes negative social connotations. Consulting firms suggest that over $\$ 2$ billion will be spent globally on blockchain solutions in 2018, while the number of blockchainrelated LinkedIn job postings more than tripled in $2017 .{ }^{1}$ However, this development is not without hype. While new partnerships, joint ventures, and projects are constantly announced, there are few examples of successful applications on a large scale. Statistics (Browne (2017)) indicate that out of the 26,000 new projects started in 2016 , only $8 \%$ were still active in 2017 . There are signs

\footnotetext{
* This article is inspired by "Distributed Ledgers and Operations: What Operations Management researchers should know about Blockchain technology," a longer manuscript by the same authors forthcoming at M\&SOM.

${ }^{1}$ https://enterprisersproject.com/article/2018/2/5-blockchain-statistics-cio-reality-check
} 
of a bubble forming in financial markets and in the broader economy. Long Island Iced Tea, for example, recently announced its move from the beverage business to blockchain mining and has changed its name to Long Island Blockchain. ${ }^{2}$ In the two days following the announcement, its stock price rose by $344 \%$.

These stories are reminiscent of the internet's development and the dotcom boom. The technology gradually emerged and became a major disruption to the global economy, went through a bubble, yet today is an important, if mundane, part of the world economy. As with the TCP/IP in its time, many recent blockchain developments are relevant to the OM research community. For example, Blockchain is capable of improving supply chain operations by providing visibility, information aggregation, information validation, contract automation, and system resiliency. Blockchain can create more stable, transparent, secured, efficient, ethical, and robust supply chains, and can also facilitate improved integration of supply chains and finance. In this paper we document its initial real-life implementations, many practical and theoretical questions remain unanswered.

A review of the technology and its limitations can be found in Hilary (2018). Importantly, a Blockchain is a specific form of distributed ledger that has a specific data structure. Other forms of distributed ledgers also exist. For example, Directed Acyclic Graphs (DAG) are the foundation of DLT such as Byteball, and DagCoin and IOTA. Unlike Blockchain (which is a sequential list of blocks), a DAG is a data structure that resembles a tree-like flow chart where all points head toward one direction. DAG hold the promise of solving some of the technological limitations that have plagued Blockchains. For example, DAG offer the possibility of greater scalability but have not yet been extensively deployed and tested at this point. There are also improvement of the Blockchain technology itself that can relax some of its constraints. For example, "sharding," is an approach that partitions the data in such a way that only a small subset of nodes has to verify a subset of transactions. This approach allows the system to process transactions in parallel.

In a companion article (Babich and Hilary (2018)), we provide a framework that conceptually frames the role of Blockchain and other DLT in OM, we provide specific examples of research questions, and we show how research in economics can inform research in OM on blockchain applications. In particular, we argue that potential research questions revolve around three main themes: information, automation, and tokenization. In this article, we revisit these themes and provide four specific examples not discussed in Babich and Hilary (2018). Specifically, we expand on these three themes in $\S 2$, while in $\S 3$, we illustrate these remarks by considering specific applications. We discuss possible future uses of the technology in $\S 4$. We conclude in $\S 5$.

\footnotetext{
${ }^{2}$ https://www.cbinsights.com/research/blockchain-hype-stock-trends/
} 


\section{Strengths and Weaknesses of Blockchain with respect to OM}

We argue in Babich and Hilary (2018) that research ideas related to blockchain applications in the OM literature cluster around three themes: information, automation, and tokenization.

\subsection{Information}

Advantages: Blockchain provides a platform for connecting multiple decision makers with multiple sources of information and generates a richer informational landscape for OM applications. There are other ways of collecting and sharing information (proprietary networked systems, smart sensors, Internet, mobile apps); blockchain technology will not supersede these, but rather complement them. The main differences between Blockchain and some of the existing technologies are the lower costs of adding new participants, data encryption, and record validation.

Disadvantages: Decision paralysis induced by information overload is likely to become more common. Information is more likely to be used for unintended purposes. False records will be more difficult to delete, and managing privacy and access rights may become difficult.

\subsection{Automation}

Advantages: Blockchain allows for faster transactions by reducing the time required to obtain confirmations from multiple participants, by providing reliable and verified information, and by allowing automation of some of the transaction logic through smart contracts. Smart contracts can automate OM transactions, increase their velocity, and facilitate complete contracts. For example, smart contracts can open areas of B2T, T2C, and T2T interactions (where T stands for Things, as in the "Internet of Things") and new sources of large up-to-date and high-quality datasets.

Disadvantages: If rules coded in smart contracts are put in place ahead of a system's deployment and are not dynamically updated, the system may become too rigid for the needs of dynamic environments. But if a smart contract logic is modified dynamically (e.g., by AI), there is the risk of AI making wrong or unethical decisions. These untoward outcomes can then lead to immutable changes in the logistics, information, and financial networks. Problems stemming from the "black box" nature of technology also increase.

\subsection{Tokenization (digital assets)}

Advantages: Blockchain can create verifiable digital claims ("tokens") corresponding to production, inventory, and financial assets, and facilitate the sharing, trading, and exchange of these assets among multiple participants. This makes the coordination of extended supply and distribution chains easier (virtual vertical integration) and the coordination of actions of firms at the same level possible (virtual horizontal coordination). The precise attribution of rights to various features of assets makes the management, exchange, and trading of these assets easier. Contracting, B2B, and $\mathrm{B} 2 \mathrm{C}$ interactions can be more formal, thereby reducing legal and transaction costs. Essentially, 
creating precisely-defined claims facilitates the development of markets (either along the supply chain or across the supply chain tiers).

Disadvantages: The danger of over-specifying contracting relationships diminishes the roles of trust and implicit contracts. Both trust and implicit contracts are essential in uncertain environments where the role of "unknown unknowns" is significant. Some of the ideas discussed below are based on classical OM problems like the bullwhip effect; others have not been studied yet. Some ideas stem from current blockchain applications. For others, we imagine novel business models. For each of the ideas, we explicitly discuss how blockchain technology can help, why it may fail, and point out promising research directions for OM researchers.

\section{Research Agenda for Blockchain Technology in OM}

We provide four examples of research areas below. In Babich and Hilary (2018), we provide additional examples.

\subsection{Crisis Management}

Figure 1 depicts recommended steps for crisis management, illustrating sequential responses to a Supply Chain Risk Management (SCRM) event ex-post. The figure is an extract from the SCRM best practices document, although the insights apply generally to any crisis (not just supply chains).

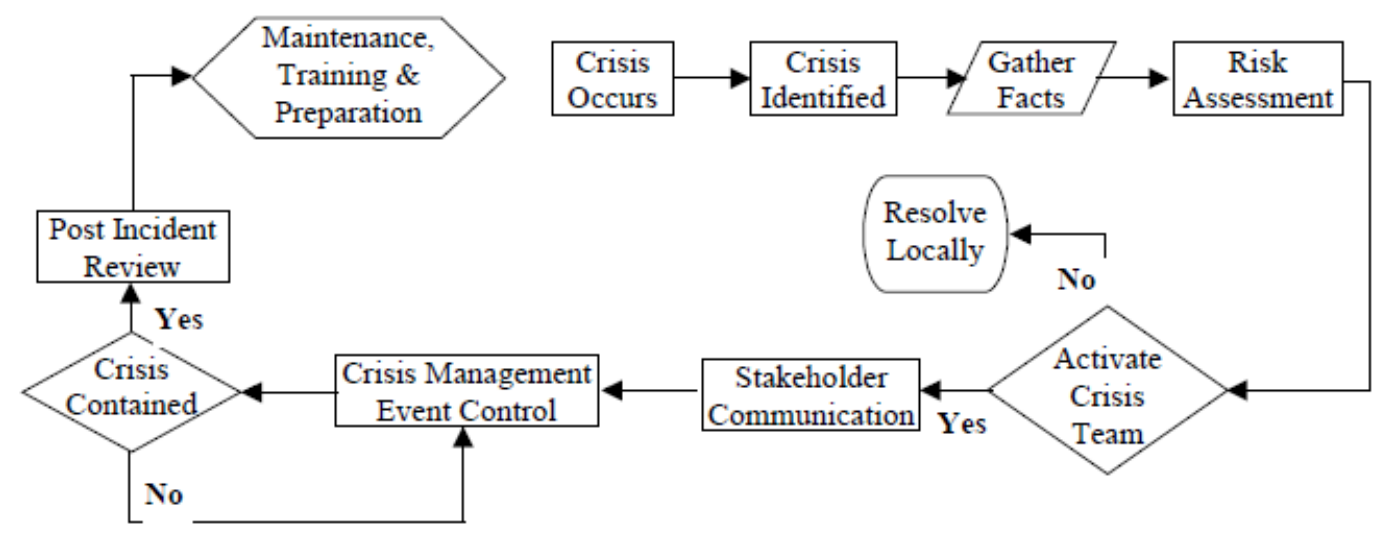

\section{Figure 1 Crisis Management Sequence}

Source: SCRM Best Practices, Section 5 (http://www.scrlc.com/articles/Supply_Chain_Risk_Management_A_ Compilation_of_Best_Practices_final[1].pdf)

Two features differentiate crisis management from risk management. First, during a crisis, time often becomes a bottleneck resource. As a pandemic spreads, for example, or as a population awaits help after a natural disaster, or as production capacity idles, damage accumulates with every passing second. Here, any interventions and resources that can shorten the duration of a crisis are beneficial. This includes the recognition that the crisis is happening now and not at some point in 
the future, not wasting time during the collection of information and the assessment of risk, having a crisis response plan in place, activating a crisis team, and notifying stakeholders without delay. Second, in the midst of a crisis, the risk management infrastructure itself can be affected, including personnel, computer and communication systems, civil infrastructure, and law enforcement and the legal system.

How can Blockchain help? The strength of Blockchain in providing visibility, aggregating information, validating it, automating execution, and system resiliency are instrumental for crisis management. Blockchain can in fact be even more beneficial for crisis management than for general SCRM (Babich and Hilary (2018)). When taking advantage of smart contracts, stakeholders and crisis management teams can be automatically notified about unfolding crises and updated on the mitigation progress. Blockchain can integrate information from a variety of sources, and so is able to provide temporary identities to the population affected by a crisis or to response personnel to facilitate the tracking of resource usage and consumption. The distributed nature of blockchain technologies makes them more robust to several types of infrastructure losses.

Why may Blockchain fail? Alas, Blockchain does require basic infrastructure to operate. A classic example is electrical failure, potentially affecting disaster response plans that may not reach personnel and stakeholders in affected areas in good time.

What is the research potential? What effect could temporary identities have on resource management? How does this relate to humanitarian logistics research? Does automating the crisis response increase or decrease risk (Hilary (2015))?

\subsection{Tokenization and Capacity Management}

OM researchers have studied the use and value of reorder options in procurement contracting (Barnes-Schuster et al. (2002), Babich (2006)). As with any valuable item, claims on capacity or reorder options can be written and traded.

How can Blockchain help? Similar to what Blockchain did for financial options and other financial securities, blockchain technology can help create a secondary market for reorder options and other forms of contract flexibility. Blockchain can also eliminate the need for the exchange to serve as middleman; retailers anticipating a higher demand will be able to purchase additional reorder options from other retailers rather than directly from the manufacturer, allowing for a more efficient reallocation of risk (risk pooling). Options will thus become more valuable and retailers more likely to order them.

Another application of blockchain technology to digital claims is the tracking of ownership of the products after sale. By keeping track of after-sales transactions, manufacturers can contact the current owner of the product in order to control operations in gray markets (i.e., the sales 
of genuine products by unauthorized retailers) and to administer warranty and reward programs. Customers too can benefit from knowing the history of products after the original sale by the Original Equipment Manufacturer (OEM). This historical record of secondhand products can thus signal the quality of the goods (e.g., Was the car in the flood zone during a hurricane? Has the medicine been kept in a dark, cool place for the duration of its life?). The validation and aggregation dimensions of blockchain technology are essential features of this application.

Why may Blockchain fail? Firms or customers may prefer for less information to be made available as greater disclosure does not obviously produce a better equilibrium. For example, manufacturers may tacitly approve of the existence of gray markets and pretend not to know about them.

What is the research potential? How can the market be implemented for non-standard claims? What are the rules for matching supply and demand over time? How much of multi-item inventory theory can be used to manage such markets? What would be the effect of secondary markets on the equilibrium purchases of reorder options? How should manufacturers adjust option prices to account for the presence of the secondary market? What degree of risk pooling can be achieved, and can the manufacturer avoid excessive capacity overinvestments?

\subsection{Blockchain in Supply Chain Finance (SCF)}

Blockchain technology has the potential to integrate Supply Chain Management (SCM) with other functions. One example, supply chain finance (SCF) is an important area in OM research (Babich and Kouvelis (2018)). The practice of SCF represents a sizeable component of the economy, as evident in the Bank for International Settlements (2014) report that trade credit accounts for $\$ 12$ trillion out of $\$ 18$ trillion in exports per year. SCF allows companies to use working capital more effectively and reduce financing costs by streamlining transactions between banks, using the credit capacity and the cost of firms with lower capital costs, and incorporating information about procurement and logistics processes. SCF solutions are typically offered by intermediaries: banks, logistics providers, and technology companies, which provide their service for a fee. Current SCF solutions typically apply to single tiers of a supply chain. SCF solutions are themselves an improvement over old ways of conducting business transactions such as letters of credit and escrow services. Letters of credit guarantee that the buyer of goods or services has the financial resources to pay (either in cash or approved line of credit). With letters of credit and escrow accounts, a third party (e.g., banks) holds the money until sale conditions have been met. Business transactions using letters of credit tend to take lengthy periods of time to clear (days or weeks) in order for multiple parties to verify different information. The following is a typical process. First, the buyer applies for the letter of credit from its bank. Second, the buyer's bank provides a letter of credit to 
the seller. Third, the seller ships the goods with the carrier and supplies a confirmation (e.g., bill of lading) to the seller's bank together with the letter of credit. Fourth, the seller's bank pays the seller and sends the letter of credit to the buyer's bank, which wires the money to the seller's bank. Fifth, the buyer's bank sends the bill to the buyer. Finally, the buyer uses the confirmation of payment to receive goods from the carrier. SCF solutions place information about sales and payment on one platform and expedite the money flow from buyer to seller. Potentially, SCF solutions take over the functions of both the buyer's and the seller's banks in providing escrow services to the transaction.

How can Blockchain help? Blockchain can help to bypass traditional SCF providers and offer SCF solutions along extended supply chains. Fundamentally, many SCF solutions focus on establishing credibly that sellers of goods have produced and shipped them and that buyers of goods have committed capital to pay for them. This is an ideal application for blockchain technologies, where claims on the ownership of the products are exchanged for claims on the ownership of some amount of cash. Furthermore, the marginal cost of adding participants to an SCF ledger can be lower than with a solution provided by a traditional SCF provider. FnConn, a subsidiary of FoxConn, announced in 2017 the launch of a blockchain-based platform for providing working capital to firms in FoxConn's supply chain. The announcement mentioned loans totaling $\$ 6.5$ million that have already been issued. ${ }^{3}$

Even with traditional SCF providers, Blockchain's strengths involve increasing visibility into higher supply chain tiers, aggregating various kinds of information, and overcoming asymmetric information and moral hazard costs that might presently restrict access to financing. For example, according to Sanne Wass, ${ }^{4}$ new pilots by Unilever, Sainsburys and Sappi together with Barclays, Standard Chartered and BNP Paribas try to use Blockchain to tie environmental impact information of supply chains to making financing available to companies. One pilot focuses on tea supply chains and participants hope to include information on 10,000 Malawian tea farmers.

Why may Blockchain fail? Some companies are reluctant to participate in SCF solutions (regardless of whether they are processed through a bank or Blockchain). Weak suppliers may feel that better information may allow more powerful buyers to take advantage of them (now or in the future) by reducing information asymmetry, unveiling supply sources, etc. Companies may not want to share SCF benefits with suppliers since helping a supplier can also help a potential competitor who shares the same supplier (Wadecki et al. (2012)).

What is the research potential? How can multi-firm SCF solutions be optimally managed? How can competitive effects between supply chains and between individual firms be accounted

${ }^{3}$ https://www.coindesk.com/foxconn-subsidiary-blockchain-supply-chain/

${ }^{4}$ https://www.gtreview.com/news/fintech/banks-to-pilot-new-concept-for-blockchain-based-supply-chain-finance/ 
for using SCF? What SCF contracts can be created using more detailed information generated by blockchain networks? There is already initial work in the OM literature on this subject. Chod et al. (2018) study how blockchain technology and the transaction verifiability it affords can be leveraged by firms to efficiently alleviate information asymmetry issues between themselves and their prospective lenders for supply chain finance.

\subsection{Fraud}

Blockchain and other Distributed Ledger Technologies (DLT) continue to produce more and more applications in product traceability and fraud mitigation. As we write, blockchain technology is being developed to track the provenance and the chain of custody of fish ${ }^{5}$ and of coffee (Naydenova (2017)). A consortium of companies led by Walmart will work with IBM to identify where global food supply chains can benefit from Blockchain. ${ }^{6}$ In response to a wave of product adulteration cases, Walmart has piloted the use of Blockchain to track pork in China (Nash (2016)). Everledger has recorded, since 2015, the provenance and the chain of custody of over two million diamonds on Blockchain. ${ }^{7}$ IBM has even proposed to the government of British Columbia to use blockchain technology to verify the provenance of legal cannabis, "from seed to sale", to multiple stakeholders (Dyble (2017)). Veridium Labs and IBM are working on a blockchain solution to improve operations of carbon-credit markets, a valuable feature given the massive fraud that has occurred in European markets. ${ }^{8}$

Why may Blockchain fail? Blockchain makes it difficult to alter a ledger once the information has been recorded, minimizing the risk of double-spending in many cases, and mitigating the risk of certain frauds. However, this point is not uniformly true. In a system that is not fully integrated (e.g., some private lenders do not have access to the full ledger), assets could be used as collateral with multi-lenders, which may make perpetrating fraud easier. Indeed, the technology could enhance fraudulent activity. For example, Zcash, a cryptocurrency implementing zk-SNARKs (a cutting-edge privacy feature), allows for unlimited and undetectable double-spending if the seed value is compromised by a bad actor. Even if the risk of double-spending is minimized, only a very specific form of fraud is mitigated. For example, any form of adulteration is not going to be detected if sensors cannot document the properties of assets from conception ("garbage in, garbage out"). This control may be easier to execute for assets that are digitally native, but even so, adulteration remains an issue. For example, trading platforms have notoriously weak defenses against hacking

\footnotetext{
${ }^{5}$ https://www.hyperledger.org/projects/sawtooth/seafood-case-study

${ }^{6}$ https://goo.gl/4Bz1JJ

${ }^{7}$ https://www.everledger.io

${ }^{8}$ https://www.marketwatch.com/story/ibm-and-veridium-labs-partner-to-use-blockchain-technology-to-improvecarbon-credit-markets-2018-05-15
} 
(e.g., Mt. Gox). ${ }^{9}$ In addition, fraudsters are likely to adapt and capitalize in ways that we do not anticipate at the moment.

What is the research potential? The main research questions relate to whether the technology will be successful. How will sensors and Blockchain be integrated into a coherent framework? Will traceability alone be sufficient or are other features needed to ensure the tools will be useful for combating fraud?

\section{Future applications}

DLT are likely to generate numerous interesting applications. For example, the city of Austin, Texas uses Blockchain to create identities for homeless. Individual will be able to log-in via public computers or phones to access Blockchain and prove their identities. The plan is to ensure coordination of delivery of services and resources by diverse organizations who are helping homeless.

One of the key features of the technology is its capacity to integrate heterogeneous systems. Industry 4.0 items such as cyber-physical systems or the Internet of Things (IoT) are likely to benefit from these developments. However, this integration can go further and offer the possibility that loosely connected economic actors interact with each other. For example, imagine that inhabitants of a city want to improve a park by planting trees but that the project is plagued by the tragedy of the commons. The project makes sense only if a sufficient number of people commit to paying for a tree. A DLT system, for example, linked to a crypto-currency could trigger an automatic payment through a smart contract once a critical mass has been reached. Meanwhile, a coffee chain is facing the need to buy carbon quotas. One way to address this issue is to buy them from the inhabitants who have planted the trees and to compensate them with free products at the store. In this setting, private and public blockchains interact seamlessly.

The integration will be implemented is likely to be affected by socio-economic considerations. For example, China is currently developing a platform to integrate information from different public and private actors to form a "social score" that can offer access to enhance services such deposit free rentals or ease of access to banking services (naturally, this can also be used for political and social monitoring). In this case, a centralized platform controlled by the government may be technologically superior.

In the US, this integration has been executed by a few large actors that have strived to established monopoly power. In this context, DLT may be seen as a threats as they can facilitate the break-downs of these large actors and the dissipation of their rent. Indeed, DLT can facilitate the ownership of information by customers and citizens instead of letting large electronic conglomerates exploiting it at a cost below its marginal value. For example, one can imagine the possibility

${ }^{9}$ https://www.wired.com/2014/03/bitcoin-exchange/ 
of micro-payments to the multitude of data owners any time an organization uses it for marketing and other commercial purposes. Recent legal developments in Europe such as the General Data Protection Regulation (GDPR) may be a first step in this direction.

\section{Conclusions}

In this article and its companion study (Babich and Hilary (2018)), we provide a research agenda for the OM field with regard to recent developments in DLT such as Blockchain. Aside from offering new and interesting ways to revisit traditional OM questions, Blockchain offers the potential to introduce exciting business models and new perspectives on classic OM problems. At the same time, we caution against falling for the hype around Blockchain. As illustrated in this paper, blockchain technologies equally offer drawbacks and challenges. For example, in private blockchain networks, supply chains become more than an integrated collection of flows and contracts; they become institutions that need to be regulated and governed as such. Blockchain development also creates interesting issues from an industrial organization perspective.

Blockchain technology promises numerous benefits. Therefore, many researchers and practitioners are asking why we have seen so few documented successes on Blockchain in OM. One simple answer is that not enough time has passed yet for technology to mature and produce results. It was first introduced ten years ago in 2008 but saw a real development only around 2015. To put things in perspective, we can look at historical precedents (Figure 2). Sir Humphry Davy invented the

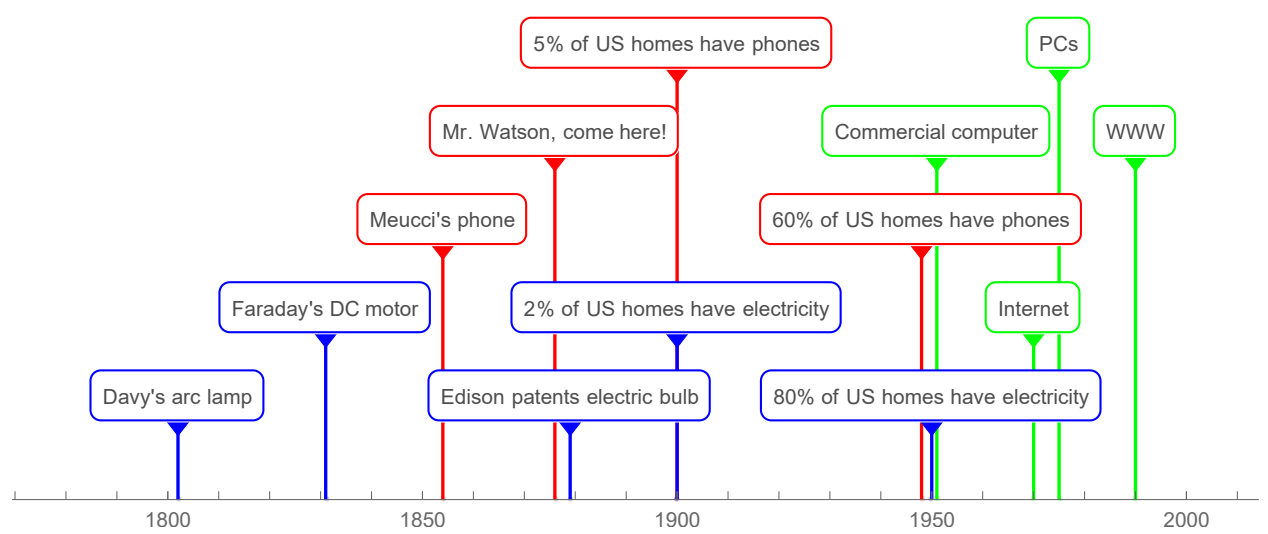

Figure 2 Timelines of major industrial developments

carbon arc lamp in 1802. Michael Faraday developed the first DC electric motor in 1831. Thomas Edison patented the first successful electric bulb in 1879. Twenty one years later, in 1900, only $2 \%$ of homes in the US had electricity. Another fifty years later, in 1950, 80\% of homes in the US had electricity. In 1854, Antonio Meucci demonstrated the first electric telephone. The first successful 
telephone call between Bell and his assistant Watson happened on March 10, 1876. Twenty four years later, in 1900, only $5 \%$ of the US households had a telephone. Another fifty years later, in 1950, approximately $60 \%$ of homes had a telephone. First commercial computer was sold in 1951. Arguably, the broadly visible impact on the society has not occurred until after the introduction of personal computers in 1975, the development of the Internet in 1970s, and addition of the World Wide Web in 1990s. Similarly, the true benefits of Blockchain technology will not be apparent for another one or two decades and most likely technologies that are not invented yet will help to realize Blockchain potential.

For instance, Blockchain might have relevance for Internet of Things, Internet of Serives, Smart Factory and Cyber-physical systems, which are the components of Industrie 4.0 initiative (Hermann et al. (2016)). The strength of Blockchain technologies that we identified are relevant for the design principles of the initiative: (1) Interoperability, (2) Virtualization, (3) Decentralization, (4) RealTime Capability, (5) Service Orientation, and (6) Modularity. Industrie 4.0 and its derivatives may be the vehicles for Blockchain revolution. Time will tell.

Perhaps what makes the lack of progress in Blockchain noticeable is the striking difference between the number of pilot projects and the number of successful business. It seems that almost every company has some Blockchain initiative of another in the works. This is to be expected. By investing now, these companies are effectively acquiring options in this technology, ensuring that

they will be among the first to benefit when hype subsides and common standards emerge. The extreme uncertainty about the technology's future only makes these options more valuable.

We believe these topics provide exciting avenues for research.

\section{References}

Babich V (2006) Vulnerable options in supply chains: Effects of supplier competition. Nav Res Log 53(7):656673.

Babich V, Hilary G (2018) Distributed ledgers and operations: What operations management researchers should know about blockchain technology, forthcoming in M\&SOM, available at https://ssrn.com/abstract $=3131250$.

Babich V, Kouvelis P (2018) Introduction to the special issue on research at the interface of finance, operations, and risk management (iFORM): Recent contributions and future directions. MESOM 20(1):1-18.

Bank for International Settlements (2014) Trade finance: Developments and issues. publication 50, Committee on the Global Financial System (CGFS), Basel.

Barnes-Schuster D, Bassok Y, Anupindi R (2002) Coordination and flexibility in supply contracts with options. MESOM 4(3):171-207. 
Browne R (2017) There were more than 26,000 new blockchain projects last year - only $8 \%$ are still active. URL http://cnb.cx/2FCWEh3, November 9, 2017. Accessed on Feb 26, 2018.

Chod J, Trichakis N, Tsoukalas G, Aspegren H, Weber M (2018) Blockchain and the value of operational transparency for supply chain finance. Working paper, MIT.

Dyble J (2017) Canada urged by IBM to use blockchain in the distribution of legal cannabis. Digital Supply Chain URL https://shar.es/1LWxfF, Nov 7, 2017. Accessed on Feb 26, 2018.

Hermann M, Pentek T, Otto B (2016) Design principles for industrie 4.0 scenarios. System Sciences (HICSS), 2016 49th Hawaii International Conference on, 3928-3937 (IEEE).

Hilary G (2015) The end of human risk management? URL https://goo.gl/aMsBJ6, November 23, 2015.

Hilary G (2018) Blockchain and other distributed ledger technologies, an advanced primer. Working paper, Georgetown University.

Nash KS (2016) Wal-mart turns to blockchain for tracking pork in china. WSJ Oct 19, https://blogs . wsj .com/cio/2016/10/19/wal-mart-turns-to-blockchain-for-tracking-pork-in-china/.

Naydenova M (2017) The world's first traceable coffee - blockchain revolution. URL https://goo.gl/ ZWYA78, Nov 7, 2017.

Wadecki A, Babich V, Wu O (2012) Manufacturers' competition and subsidies to suppliers. Gurnani H, Mehrotra A, Ray S, eds., Managing Supply Disruptions, 141-163 (London: Springer-Verlag Ltd.). 